\title{
Labor Utilization and Nonwage Labor Costs in a Disequilibrium Macro Framework*
}

\author{
Horst Entorf
}

Université Catholique de Louvain, Belgium

Heinz König

University of Mannheim and Center for European Economic Research, Mannheim, Germany

\section{Winfried Pohlmeier}

University of Mannheim, Germany

\begin{abstract}
The literature on labor utilization and nonwage labor costs is extended to incorporate recent approaches to macroeconomic disequilibrium modeling based on the "smoothing by aggregation" principle. This leads to a reformulation of the basic Sneessens-Drèze type model by treating employment and working hours as separate inputs. The inclusion of nonwage labor costs serves a double purpose: first, they represent a restriction in the profit maximizing process and, second, they serve as a proxy for the fixity of labor. The results differ substantially from simulation studies that disregard the utilization of labor and the nonlinear structure of labor costs.
\end{abstract}

\section{Introduction}

While micro studies in general distinguish very carefully between stocks and flows of employment and the interaction among them, criticism has been raised, by e.g. Hart et al. (1988), that "almost without exception, macroeconomic models do not separate the important components of labor input and they come nowhere near to measuring relative factor prices accurately" (p. 99). This misspecification may have serious implications for policy recommendations. Even if scale impacts are accurately determined

\footnotetext{
*An earlier version of this paper was presented at the EC conference on "New Issues in Wages, Non-wages and Unemployment", Corsendonk, Belgium, September 1988. This research was completed when the third author was John F. Kennedy Fellow at Harvard University. We would like to thank the conference participants as well as our colleagues at Harvard, Louvain and Mannheim and two anonymous referees for their helpful comments. Financial support from the Commission of European Communities, the Deutsche Forschungsgemeinschaft, Fritz-Thyssen-Stiftung, and the German Marshall Fund is gratefully acknowledged.
} 
in macroeconomic models, the omission of separate treatment of labor stocks and labor utilization may be responsible for optimistic predictions about employment responses due to, for instance, reductions in weekly working hours. However, microeconomic approaches which endogenize labor stock (employment) and labor utilization (hours) as separate factor inputs and which model corresponding relative factor prices usually operate in a partial equilibrium framework, where variables that are likely to be linked to other important macroeconomic aggregates are held fixed.

We extend the literature on labor utilization and nonwage labor costs, e.g. Hart (1987) and König and Pohlmeier (1988, 1989), to incorporate recent approaches to macroeconometric disequilibrium modeling based on Lambert's (1988) "smoothing by aggregation" principle. This approach seems promising to us, for several reasons. First, several studies show that macroeconometric disequilibrium models reflect European labor market phenomena appropriately and serve as an excellent tool for disentangling the various sources of unemployment. Second, the effectiveness of a reduction in working hours depends heavily on the prevailing rationing scheme; see Toedter (1988). Hence, a disequilibrium approach that allows for the simultaneous existence of different rationing schemes on the micro level appears to be a natural starting point for analyzing policies such as a reduction in standard working hours, taxation of overtime work or reduction in nonwage labor costs.

This paper is organized as follows. Section II focuses on some general properties of a macroeconomic rationing model in which micro markets that belong to different regimes are smoothed by aggregation. The framework follows an approach suggested by Sneessens and Drèze (1986) and adapted in a paper by Entorf et al. (1990) to the German economy. The model is generalized by distinct treatment of labor stock and working hours as input factors in the production process. We also discuss the concepts used to distinguish between Keynesian, classical and repressed inflation demand for labor. We then turn to the underlying microeconomic theory of a firm which maximizes profits, given a nonlinear cost function and a technology with capital, labor stock and labor utilization as inputs. Estimates of technology equations and an employment function are presented in Section III. In contrast to earlier work, we endogenize the mismatch of labor and separate the mismatch of supply and demand into the components capital and labor mismatch. The formulation of wage and price equations allows for the adjustment of relative factor costs and, hence, for feedback on the choice of the optimal technology. In Section IV, we simulate the effects of a reduction in standard working hours. In contrast to views more in favor of positive employment effects due to reduction in hours, we conclude that nonwage labor costs combined with firms' opportunities to increase labor utilization through overtime will 
induce negative employment effects. On the other hand, reducing statutory nonwage labor costs seems to be a preferable strategy in fighting unemployment.

\section{Theoretical Considerations}

\section{The Conceptual Framework}

Sneessens and Drèze (1986) have formulated their approach in the framework of Barro-Grossman-Benassy-Malinvaud, where price and wage rigidities prevent markets from clearing. Hence, output $Y_{i}$ of any market and at any point in time is restricted by either insufficient demand for goods, insufficient capacity or lack of labor. Rationing on market $i$ of the goods market can therefore be described as:

$$
Y_{i}=\min \left(Y D_{i}, Y P_{i}, Y S_{i}\right) \text {, }
$$

where $Y D_{i}$ represents demand for goods, $Y P_{i}$ output at full capacity and $Y S_{i}$ maximal output determined by the available amount of labor supply $L S_{i}$.

Given these output constraints, we observe $L D_{i}$ (demand-determined employment, also called Keynesian labor demand), $L P_{i}$ (capacity determined employment, also called potential employment or classical employment) or $L S_{i}$ (labor supply) as counterparts on the labor market. Hence, the min-condition for the labor market is:

$$
L_{i}=\min \left(L D_{i}, L P_{i}, L S_{i}\right) \text {. }
$$

Under some general assumptions, Lambert (1988) has shown that after aggregation over micro markets, $L$ is simply obtained directly as a function of aggregated $L D, L P$ and $L S$ in a CES-type functional form:

$L=\left[L D^{-\rho}+L S^{-\rho}+L P^{-\rho}\right]^{-1 / \rho}$,

where $\rho$ can be interpreted as a parameter of mismatch. For $\rho \rightarrow \infty$, equation (3) boils down to the usual min-condition, i.e., the aggregate economy is subject to only one of the constraints.

The key question is how to get measures of the unobservable variables $L P$ and $L D$. They can easily be constructed by using optimal productivities of capital and labor $(Y / K)^{*}$ and $(Y / L)^{*}$, respectively, which make sure that the given availability of factor inputs will be used to determine the maximal production level. With these so-called technical productivities, we can determine $Y P=(Y / K)^{*} K$, where $K$ represents installed capacity, $L P=(Y / L)^{*-1} Y P$ and $L D=(Y / L)^{*-1} Y D$. Due to these crucial definitions, the choice of the correct production technology becomes the cornerstone of the model. In the work of Sneessens and Drèze, as well as in subsequent 
papers by e.g. Entorf et al. (1990), it is assumed that observed productivities do not coincide with the optimal ones because of unused capital and labor hoarding phenomena. In addition, theoretical considerations and econometric evidence reveal that firms choose the level of labor utilization through overtime work; see e.g. Hart (1987) and König and Pohlmeier (1988). Consequently, in this paper, we introduce a technology that treats employment and hours worked separately (Section II).

\section{The Technology}

Since factor substitution is supposed to be possible only in the long run, variations in the utilization of factor inputs play a crucial role in the short run. Previous studies using the Sneessens-Drèze model account for the difference between actual (observed) and potential (technical) productivities by introducing exogenous utilization rates for capital and labor. As regards our approach, labor utilization measured as average hours worked can be controlled by firms through overtime work (and possibly short-time work), i.e., we allow for nonperfect substitution between employment and hours, as proposed by Feldstein (1967), Bernanke (1986) and others. Moreover, the treatment of employment and hours as distinct labor inputs gives rise to a nonlinear labor cost scheme. In particular, we assume that production costs are given by

$C=P_{i} K+\left[\bar{w} \bar{H}+w^{*}(H-\bar{H})\right] L+[b+v H] L$,

where $K$ denotes capital input that can be purchased at constant unit usage costs $P_{i}$. Labor costs consist of wage and nonwage labor costs. Wage payments per worker are $\bar{w} \bar{H}+w^{*}(H-\bar{H})$, where $\bar{w}$ denotes the standard wage rate, $w^{*}$ the overtime wage rate, $\bar{H}$ standard hours and $H$ effective working hours. Nonwage labor costs per worker, $b+v H$, consist of fixed nonwage labor costs, $b$, and variable nonwage labor costs, $v H$. By definition, the latter can be controlled by firms through the utilization of labor.

Due to the interaction of $L$ and $H$ in (4), closed-form solutions of conditional factor demands for workers and hours are only available for simple functional forms of the production function (e.g. Cobb-Douglas function). Moreover, second-order conditions do not necessarily hold. A simple way to circumvent the problems arising from the nonlinearity of labor costs is to express them in terms of labor volume $(V=L \cdot H)$ and employment:

$C=P_{i} K+\left[\bar{w} \bar{H}+w^{*}(H-\bar{H})\right] L+[b+v H] L$,

where $Q=\left(\bar{w}-w^{*}\right) \bar{H}+b, \tilde{W}=w^{*}+v$.

Production costs in (5) are linear in $K, L$ and $V$. Hence, all difficulties due to the nonlinearity of costs disappear if the firms' optimization problem 
can be redefined in terms of $L, V$ and $K .^{1}$ For the technology, we assume the following CES-type production function:

$$
Y P=\left[\delta_{1}\left(\mathrm{e}^{a_{1} t} L P \cdot H\right)^{-(1-\sigma) / \sigma}+\delta_{2}\left(\mathrm{e}^{a_{2} t} L P\right)^{-(1-\sigma) / \sigma}+\delta_{3}\left(\mathrm{e}^{a_{3} t} K\right)^{-(1-\sigma) / \sigma}\right]^{-\sigma /(1-\sigma)} .
$$

The production function has constant returns to scale in employment and capital, i.e., potential output $Y P$ doubles when potential employment $L P$ and capital are doubled for a given utilization of labor, but increases more than proportionally when hours are also increased. Note that the parameter $\sigma$ can only be regarded as the elasticity of substitution if the model is set up in terms of $V, L$ and $K$. In its original form, the technology reveals a variable elasticity of substitution. Profit maximization implies the following relationships for output per man-hour, output per worker and the outputcapital ratio:

$$
\begin{aligned}
& (y-l-h)^{*}=\text { const. }+\sigma(\tilde{w}-p)+(1-\sigma) \alpha_{1} \cdot t, \\
& (y-l)^{*}=\text { const. }+\sigma(q-p)+(1-\sigma) \alpha_{2} \cdot t, \\
& (y-k)^{*}=\text { const. }+\sigma\left(p_{i}-p\right)+(1-\sigma) \alpha_{3} \cdot t .
\end{aligned}
$$

Lower-case letters denote logs of the variables. Interestingly, optimal labor utilization, which is determined by the difference between (7) and (8), is scale independent. This strong property guarantees that optimal labor utilization is only affected by technical progress in a growing economy with stable relative prices. ${ }^{2}$ However, labor utilization varies over the cycle through changes in relative factor prices. Contrary to conventional macroeconomic systems, labor cost parameters such as standard wage rate, standard hours and nonwage labor costs enter into the model based on an optimizing behavior. For fully utilized production capacities, potential output and potential employment are determined by:

$y p=(y-k)^{*}+k$.

$l p=y p-(y-l)^{*}$.

Because of the linearity of the system (7)-(9), it is easy to introduce a partial adjustment mechanism in order to account for a slow adjustment of the factor productivities to relative price changes. There is strong econometric evidence from quarterly data that employment and hours adjust very quickly to their desired values; cf. e.g. Hamermesh (1986) on 12

\footnotetext{
${ }^{1}$ The simplest case is the Cobb-Douglas form $Y=N^{a} H^{\beta} K^{\gamma}$, which can be redefined as $Y=V^{\beta} N^{a-\beta} K^{\gamma}$.

${ }^{2}$ König and Pohlmeier (1988) estimate a nonhomothetic version of the Generalized Leontief System. Their estimates reveal that the outrageous assumption of scale independence of hours frequently used in theoretical models is not too far-fetched.
} 
OECD countries including West Germany. Thus, we assume perfect adjustment of employment and hours within a year in the econometric model based on annual data, but introduce a partial adjustment mechanism for the capital equation (9). Various attempts to allow for partial adjustment in employment and working hours resulted in insignificant adjustment coefficients, thereby indicating that the assumption of perfect adjustment of these variables within a year seems appropriate.

\section{The Estimations in a Disequilibrium Macro Framework}

\section{The Technology}

In order to take into account differences between observable and optimal capital productivity, we include capacity utilization DUC as an additional explanatory variable. DUC is obtained from business-survey data collected by the Ifo Institute (Munich). User costs of capital are approximated by the price of investment goods, which implies the assumption of a constant long-term real interest rate. A rather serious practial problem in implementing the model econometrically is to obtain data that distinguish between variable and fixed nonwage labor costs. Since an accurate distinction between employment and hours is central to our overall analysis, we adopted two approaches. First, we treat nonwage labor costs as completely fixed by assuming $\tilde{w}=w^{*}$. In the second approach, we used estimates by Hart and Kawasaki (1987) for variable and fixed nonwage labor costs based on the sample period 1963-81. Since the quality of fit and plausibility of simulation results of the latter approach were qualitatively inferior, we only report the results of the first approach using the longer sample period 1962-86.

After appropriate detrending transformations ${ }^{3}$ and after introducing a partial-adjustment process for $(y-k)^{*}:=(y-k)-\alpha d u c$, we get the following 2SLS estimates (standard errors in parentheses, " " indicates restricted estimates):

$$
\begin{aligned}
(y-l-h)^{*} & =0.504+0.189\left(w^{*}-p\right) \\
& (0.02) \quad(0.03) \\
+(1-0.189) & \left(0.079 t+-0.001 t^{2}\right) \\
& \sim \quad(0.008) \quad(0.0002) \\
S E E & =0.012 \quad D W=1.74
\end{aligned}
$$

\footnotetext{
${ }^{3}$ Since trended data on the r.h.s. and I.h.s. would lead to some serious problems due to multicollinearity and spurious regressions, we have made the data stationary by following Sims' (1972) suggestion of using a filter $x_{t}:=x_{t}-0.75 x_{t-1}$, which we applied to all data for the technology equations.
} 


$$
\begin{gathered}
(y-l)^{*}=1.06+0.189(q-p) \\
(0.09) \sim \\
+(1-0.189) 0.018 t \\
\sim(0.004) \\
S E E=0.016 \quad D W=1.96 \\
(y-k)-0.22 d u c=0.71\left(-0.21+0.189\left(P_{i}-P\right)\right. \\
(0.10) \quad(0.26)(0.03) \sim \\
+(1-0.189) 0.010 t) \\
\sim(0.006) \\
+(1-0.71)\left((y-k)_{-1}-0.22 d u c_{-1}\right) \\
\sim \quad \sim \\
S E E=0.017 \quad D W=2.08 .
\end{gathered}
$$

The estimate of the substitution parameter is about $0.19:{ }^{4}$ In comparison to traditional two-factor approaches, this coefficient seems rather low, but simulation experiments show that this result leads to marked substitution effects between hours worked and employment. The composition of a positive linear and a negative quadratic term in the time trend component of $(y-l-h)^{*}$ implies technical progress of 0.075 in 1962, 0.05 in 1973 and a still positive value of 0.025 in 1986 .

\section{The Employment Submodel}

The Sneessens-Drèze employment equation as specified in (3) does not distinguish between "capacity mismatch" (i.e., the inadequacy of available installed capacities to match the composition of the demand for goods) and "labor mismatch" (i.e., the mismatch between labor demanded and supplied, e.g. due to qualification, location and other labor market inflexibilities). Following Gagey et al. (1990), we assume that firms determine employment in a two-stage process. First, labor demand is determined on the goods market according to

$l g_{i}=\min \left(l d_{i}, l p_{i}\right)$

and, second, demand for labor is confronted with available supply

$l_{i}=\min \left(\min \left(l d_{i}, l p_{i}\right), l s_{i}\right)$.

Assuming, as an approximation, that the minimum of lognormally distri-

\footnotetext{
${ }^{4}$ It can be shown that this indicates an elasticity of substitution between labor and capital greater than 0.19 for the original model.
} 
buted variables is itself lognormally distributed, ${ }^{5}$ the aggregation procedure yields a nested CES-functional form:

$L=\left[\left(L D^{-\rho_{1}}+L P^{-\rho_{1}}\right)^{\rho_{2} / \rho_{1}}+L S^{-\rho_{2}}\right]^{-1 / \rho_{2}}$.

This specification allows us to distinguish between "capacity mismatch" $\rho_{1}$ and "labor mismatch" $\rho_{2}$. For $\rho_{2}$ we assume that labor market inflexibilities are represented by the replacement ratio and the ratio of nonwage labor costs to total labor costs. The first variable serves as the conventional proxy for the opportunity costs of being unemployed; it might explain a degree of mismatch caused by voluntary unemployment (e.g. search unemployment). The ratio of nonwage labor costs to total labor costs serves as a proxy for the degree of fixity of labor. Following the arguments in the literature on labor as a quasi-fixed factor, we assume that with increasing fixity, labor is less mobile and does not adjust sufficiently to changes in market conditions.

There are, of course, several labor market theories, such as the efficiency wage theory, the insider-outsider hypothesis and the contract theory, that include similar variables in order to explain unemployment. The various forms of efficiency wage models and contract models elucidate that the replacement ratio might also be a factor which explains labor demand. In this sense, our approach of introducing the replacement ratio, $r$, and the ratio of nonwage labor costs to total wage costs, $s b v$, as explanatory variables of the mismatch parameter is somewhat more general than introducing these variables within the traditional demand and supply framework. The coefficient $\rho_{2}$ is simply modeled by a constant and a dummy beginning in 1974 and reflecting the effects of OPEC I on capital utilization. Estimates of (17) are given by (standard errors in parentheses):

$$
\begin{aligned}
& L=\left[L G^{-\rho_{2}}+L S^{-\rho_{2}}\right]^{-1 / \rho_{2}}+0.013 D 70+0.017 D 75 \\
& \text { (0.005) (0.005) } \\
& L G=\left[L D^{-\rho_{1}}+L P^{-\rho_{1}}\right]^{-1 / \rho_{1}} \\
& \rho_{1}=\underset{(5.1)}{4} \underset{(4.3)}{\sin } \underset{(1.03}{(4)} \quad D= \begin{cases}1 & \text { since } 1974 \\
0 & \text { elsewhere }\end{cases}
\end{aligned}
$$

\footnotetext{
${ }^{5}$ Smolny (1990) has shown numerically that for an equation of the form $L=\left(L G^{-\rho}+L S^{-\rho}\right)^{-1 / \rho}$,

the approximation is very close to an identity. For observed data $0.9 \leq L S / L G \leq 1.1$, the approximation error is less than 0.075 per cent. He further shows that for realistic situations (leading to a structural unemployment rate of 4 per cent), the minimum of two lognormally distributed random variables is also approximately lognormally distributed. The error of the cumulative distribution function is always less than $0.025 \cdot 10^{-3}$.
} 
$\rho_{2}=392.6-729.5 s b v-20.9 r r$

(124.0) (168.6)

$S E E=0.0043 \quad D W=1.78 \quad S M P L=1961-86$.

Since the CES-parameters enter equation (18) with a negative sign, estimates are as expected. Both nonwage labor costs and the replacement ratio increase labor market mismatch, while capacity mismatch is significantly higher since OPEC I.

\section{Wages and Prices}

The wage setting behavior in this model diverges somewhat from traditional concepts in macroeconometric models. Since firms can control labor utilization via overtime work, neither labor costs per employee nor net income per employee can be used as a dependent variable in a wage equation. These two variables are determined by the structure of labor costs and the resulting degree of labor utilization. Since standard wages are the major issue unions and employers' associations negotiate for in wage bargaining rounds, we treat the standard wage rate as an endogenous variable in the wage equation. Particular attention is given to the influence of nonwage labor costs on prices, standard wages and overtime wages, which are all responsible for determining relative prices of the technology equation."

Production prices are assumed to react as markup pricing on several types of costs, where the markup factor itself depends on demand conditions on the goods market. The latter are approximated by capacity utilization, DUC. As cost-push factors we use unit wage costs, i.e., standard wages relative to actual labor productivity, prices of imported goods $\left(p_{m}\right)$ relative to the $Y$ deflator, value-added taxes (tax), and nonwage labor costs relative to total labor costs.

Our 3SLS estimates of the price and the negotiated wage equation below imply a substantial degree of price rigidities. A 1 per cent increase in unit wage costs results in a short-term impact on inflation of 0.4 and a long-run effect of 0.6 . This corresponds roughly to the average share of labor income. The coefficient associated with an increase in value-added taxes does not differ significantly from unity, implying that firms pass on higher taxes to customers. The coefficient of $s b v$ reveals the specific impact of nonwage labor costs in addition to the impact of standard wages on product prices.

\footnotetext{
${ }^{6}$ Overtime wages are linked to standard wages by a premium factor: $w^{*}=\left(1+\alpha_{w}\right) \bar{w} . \alpha_{w^{\prime}}$ is assumed to be 20 per cent.
} 


$$
\begin{aligned}
& \Delta p=0.012+0.398 \Delta(\bar{w}-(y-l-h))+1.082 \Delta \operatorname{tax} \\
& (0.003)(0.04) \\
& +0.075 \Delta\left(p_{m}-p\right)_{-1}+0.107 \Delta d u c+0.840 \Delta s b v \\
& \text { (0.02) } \\
& \text { (0.04) } \\
& +0.346 \Delta p_{-1} \\
& \text { (0.08) }
\end{aligned}
$$$$
S E E=0.0042 \quad D W=1.65 \quad S M P L=1962-86
$$$$
\Delta \bar{w}=0.795(\Delta(y-l-h)+\Delta p)-0.266 \Delta U R
$$$$
\begin{aligned}
& (0.03) \\
+ & 0.297 \Delta \bar{w}_{-1}-0.417\left(\bar{w}_{-1}-0.795(y-l-h+p)_{-1}\right.
\end{aligned}
$$

$$
\left.+0.266 U R_{-1}+0.433\right)
$$

$$
S E E=0.022 \quad D W=2.10 \quad S M P L=1962-86
$$

The dependent variable of the wage equation is the growth rate of hourly standard wages. The elasticities with respect to prices and labor productivity are below unity, indicating that in the bargaining process, productivity progress and inflation are only partly passed on to higher standard wages, because the remaining margin is paid as nonwage income. ${ }^{7}$ The unemployment rate, UR, has the expected sign but reveals only poor significance.

\section{The Reduction in Standard Working Hours: Evidence from Model Simulation}

We now present simulations of the model; for details of the methodological approach, see Entorf et al. (1990). Table 1 contains results for a reduction in standard working hours by 6.25 per cent, i.e., a cut in hours from 40 to 37.5 per week. This corresponds to the strategy of German labor unions used in recent wage negotiations to fight unemployment. In contrast to results of macroeconometric model simulations which indicate positive employment impacts, e.g. Henize (1981), the results here confirm qualitatively results by König and Pohlmeier $(1988,1989)$ based upon a partial equilibrium approach. If effective working hours are determined endogenously by optimization behavior of firms, a reduction in standard working hours will ceteris paribus increase the burden of fixed nonwage labor costs

\footnotetext{
${ }^{7}$ This supposition has been tested by Entorf et al. (1990), where labor costs are used as dependent variable. In this case, the hypothesis of unit elasticities has been tested and could not be rejected by the data.
} 
Table 1. Reduction of standard working hours*

\begin{tabular}{lllllll}
\hline $\begin{array}{l}\text { Effect } \\
\text { on } \\
\text { year }\end{array}$ & $Y$ & $L^{\prime}$ & $L P^{\prime}$ & $L D^{\prime}$ & $U R^{2}$ & $H$ \\
\hline 1982 & $\pm 0.0 \%$ & $-71(0.3 \%)$ & $-67(0.3 \%)$ & $-80(0.3 \%)$ & +0.3 & $+0.3 \%$ \\
1983 & $\pm 0.0 \%$ & $-54(0.3 \%)$ & $-67(0.3 \%)$ & $-54(0.3 \%)$ & +0.2 & $+0.3 \%$ \\
1984 & $\pm 0.0 \%$ & $-48(0.2 \%)$ & $-53(0.2 \%)$ & $-54(0.3 \%)$ & +0.2 & $+0.3 \%$ \\
1985 & $\pm 0.0 \%$ & $-40(0.2 \%)$ & $-47(0.2 \%)$ & $-52(0.2 \%)$ & +0.2 & $+0.2 \%$ \\
\hline
\end{tabular}

${ }^{*} \bar{H}$ is reduced by $6.25 \%$. This is equivalent to a cut from 40 to 37.5 in terms of working hours per week, 'in thousands, 'in percentage points.

Table 2. Constant nonwage labor costs*

\begin{tabular}{|c|c|c|c|c|c|c|c|c|}
\hline $\begin{array}{l}\text { Effect } \\
\text { on } \\
\text { year }\end{array}$ & $\begin{array}{l}Y \\
(1)\end{array}$ & $\begin{array}{l}L^{\prime} \\
(2)\end{array}$ & $\begin{array}{l}U R^{2} \\
(3)\end{array}$ & $\begin{array}{l}H \\
(4)\end{array}$ & $\begin{array}{c}Y \\
(5)\end{array}$ & $\begin{array}{l}L^{\prime} \\
(6)\end{array}$ & $\begin{array}{l}U R^{2} \\
(7)\end{array}$ & $\begin{array}{l}H \\
(8)\end{array}$ \\
\hline 1982 & $+0.4 \%$ & $+424(2.0 \%)$ & -1.8 & $-1.7 \%$ & $+0.2 \%$ & $+354(1.6 \%)$ & -1.5 & $-1.6 \%$ \\
\hline 1983 & $+0.8 \%$ & $+647(3.0 \%)$ & -2.8 & $-2.6 \%$ & $+0.5 \%$ & $+573(2.7 \%)$ & -2.4 & $-2.5 \%$ \\
\hline 1984 & $+1.4 \%$ & $+888(4.2 \%)$ & -3.8 & $-3.1 \%$ & $+0.5 \%$ & $+647(3.0 \%)$ & -2.8 & $-2.9 \%$ \\
\hline 1985 & $+2.1 \%$ & $+1093(5.1 \%)$ & -4.6 & $-3.4 \%$ & $+0.2 \%$ & $+567(2.7 \%)$ & -2.4 & $-2.9 \%$ \\
\hline
\end{tabular}

${ }^{*}$ In columns $(5)-(8), b$ is kept constant at its 1981 level, $s b v$ and $r r$ enter the employment function with their actual data 'in thousands, 'in percentage points.

per worker. On the one hand, this induces substitution of labor by capital; on the other hand, firms will increase effective working hours in order to lower the share of nonwage labor costs per hour. The model displays these effects. The stock of labor will decrease by roughly 0.2 per cent and effective working hours will increase by almost the same percentage.

Since statutory social security payments comprise around 17 per cent of total labor cost in West Germany (in comparison to 7.8 and 9.5 per cent for the U.S. and the U.K. in 1981, respectively), it is interesting to check the degree to which employment reacts to changes in nonwage labor costs (possibly caused by alternative social security policies). Table 2 contains simulation results of a scenario in which nonwage labor costs are kept constant at the level in 1981. In this year, the average nonwage labor costs per worker amounted to DEM 17,000, compared to roughly DEM 23,000 in 1985 . Such a strategy would have resulted in an increasing growth rate of $Y$, a considerable increase in employment and, therefore, a reduction in the unemployment rate of between 1.8 and 4.6 percentage points. Although at first glance, one may wonder about the magnitude of these effects, the mechanisms are very simple: the reduction in nonwage labor costs induces ceteris paribus a higher demand for labor stock. The corresponding reduction in unemployment leads to an increase in the 
nominal wage rate and, in turn, in prices. However, given parameter estimates in both the wage and the price equations, prices change at a lower rate than wages. Consequently, the real overtime premium will be pushed upward, inducing a decrease in effective working hours. Therefore, both components, $L D$ and $L P$, in the employment function will increase. The use of a more labor-intensive technology requires that more workers be employed if production is equal to total demand. Similarly, for the production level corresponding to full capacity output, more workers are needed, i.e., $L P$ will increase.

Columns 5-8 of Table 2 evaluate the effects of nonwage labor costs on mismatch. Here, $s b v$ and $r r$ enter the employment function with their actual data. Results reveal that almost half of the employment effect is caused by changes in mismatch in the employment function. Lowering nonwage labor costs (and therefore mismatch) weakens the influence of the limiting factor. In view of the differences between the two simulations, a "mental reservation" seems appropriate. It should be stressed that endogenization of the structural mismatch covers only some aspects of sources of mismatch. It attributes other factors of mismatch to nonwage labor costs, which may be correlated in a historical context, but are not reversible. The proposed specification in the employment function might introduce some element of spurious regression. In spite of these deficiencies, however, we are inclined to think that both experiments reveal the importance of nonwage labor costs in the malfunctioning of the labor market.

\section{Conclusions and Perspectives}

In contrast to many other macroeconometric models that neglect the different cost components of labor, we were able to disentangle these components and include them in a macroeconometric system of the Sneessens-Drèze type. The labor cost parameters enter the system according to a microeconomic foundation and give rise to an investigation of labor cost parameter changes such as nonwage labor costs and standard working hours on macroeconomic aggregates. Not surprisingly, our simulation results differ substantially from the results of simulation studies that disregard the utilization of labor and the complex (nonlinear) structure of labor costs. Direct institutional cuts in hours are not very promising for stimulating employment.

It seems unnecessary to emphasize the deficiencies of the modeling strategy applied here. Future research should focus on labor supply, since shorter working time has become increasingly important in labor market negotiations in many European countries. Standard hours and other components of labor contracts should be treated as endogenous variables. 


\section{References}

Bernanke, B. S.: Employment, hours, and earnings in the depression: An analysis of eight manufacturing industries. American Economic Review 76, 82-109, 1986.

Entorf, H., Franz, W., König, H. \& Smolny, W.: The development of German employment and unemployment: Estimation and simulation of a small macro model. In J. H. Drèze \& C. Bean (eds.), Europe's Unemployment Problem, MIT Press, Cambridge, 1990.

Feldstein, M. S.: Specification of labour input in the aggregate production function. Review of Economic Studies 34, 375-86, 1967.

Gagey, F., Lambert, J. P. \& Ottenwaelter, B.: Structural mismatch, demand and capacity constraints in the rise of French unemployment. In J. H. Drèze \& C. Bean (eds.), Europe's Unemployment Problem, MIT Press, Cambridge, 1990.

Hamermesh, D. S.: The demand for workers and hours and the effects of job security policies: Theory and evidence. NBER WP No. 2056, October 1986.

Hart, R. A.: Working Time and Employment. Allen and Unwin, London, 1987.

Hart, R. A., Bell, D. N. F., Frees, R., Kawasaki, S. \& Woodbury, S. A.: Trends in Non-Wage Labour Costs and their Effects on Employment. Official Publications of the European Communities, Luxembourg, 1988.

Hart, R. A. \& Kawasaki, S.: Payroll taxes and factor demand. In R. G. Ehrenberg (ed.), Research in Labor Economics 9, JAI Press, Greenwich, CT, 1987.

Henize, J.: Can a shorter workweek reduce unemployment? A German simulation study. Simulation, La Jolla, CA, 1981.

König, H. \& Pohlmeier, W.: Worksharing and factor prices: A comparison of three flexible functional forms for nonlinear cost schemes. Journal of Institutional and Theoretical Economics 145.343-57, 1989.

König, H. \& Pohlmeier, W.: Employment, labour utilization and procyclical labour productivity. Kyklos 41, 551-72, 1988.

Lambert, J. P.: Disequilibrium Macroeconomic Models. Cambridge University Press, Cambridge, 1988.

Sims, C. A.: Money, income, and causality. American Economic Review 62, 540-52, 1972.

Smolny, W.: Macroeconomic consequences of international labour migration. Simulation experience from an econometric disequilibrium model. Universität Konstanz, SFB 178, Internationalisierung der Wirtschaft, Diskussionsbeiträge Serie 11-123, 1990.

Sneessens, H. \& Drèze, J. H.: A discussion of Belgian unemployment, combining traditional concepts and disequilibrium econometrics. Economica 53, Supplement, 89-119, 1986.

Toedter, K.-H.: Effects of shorter hours on employment in disequilirium models. European Economic Review 32, 1319-33, 1988. 